\title{
The challenges of digital transformation: Case of Tunisian companies
}

\author{
Amine Ben Hadj Hassine \\ Department of Management Sciences, Higher Institute of Informatics and Management of Kairouan, Kairouan University, Kairouan, 3100, Tunisia
}

\begin{abstract}
The objective of this article is to identify the challenges of Tunisian small and medium-sized enterprises (SMEs) in the implementation of Industry 4.0. Indeed, the Subject of Digital Transformation has its relevance as Industry 4.0 is considered as the first industrial revolution to be predicted before it happened. Competition from digital companies is disrupting business models, and leaders no longer have a choice: the time has come for digital transformation (Dussart, C, 2015). This transition is not new. It covers a necessary reality, especially for so-called traditional companies, which were not born in digital culture. Built on an old model, they must initiate and succeed in their transformation to remain competitive. This paper aims to analyze the opportunities brought by digital transformation for Tunisian companies. In our research and on the methodological section, we used an exploratory qualitative approach with Tunisian companies, using a questionnaire. The results of this investigation have shown that the great opportunities and challenges facing Tunisian companies are human capital in the first place, funding and above all methodological support. And the government must be the first to assist and support the digitization process.
\end{abstract}

Keywords: Digital transformation, Tunisian companies, challenges, opportunities.

\section{Introduction}

According to the Global Innovation Index, technology and innovation drive the economic growth. Thus, the level of economic development of a country depends closely on its innovation index. In fact, the Tunisian SME needs support programs and structures in its transformational approach so that it can disengage from traditional practices and effectively adopt digitalization. Indeed, those companies are urgently called upon to reconfigure all their processes as well as the way they interact with their stakeholders and the external environment in general.

In fact, digitization is one of the major challenges for Tunisian SMEs which are now obliged to engage in this transformation which requires changes at several levels such as the Business Model which should be more disruptive, the Business Processes reinvented since the offer is now increasingly digitalized without forgetting the Customer Journey in the presence of a new type of consumer who is more connected, more mobile, and more demanding.

Forced to face this situation, digital transformation can be considered a source of anxiety for top management, because they must reshape their old working methods and redefine many parameters of their strategies such as teamwork, relationships with all stakeholders, organizational culture, creativity, and innovation. Through this paper, we wish to enrich the inquiries made in the context of emerging economies and dealing with the case of small and medium-sized enterprises facing digital transformation, their degree of maturity to integrate and adapt to the requirements of Industry 4.0. Thus, we try to answer the following main research question: How do business leaders perceive this digital transformation?

In fact, the degree of adoption of advanced ICTs among Tunisian SMEs is relatively limited or almost among the lowest rates in the MENA region due to a diversity of factors such as financial and human resources, which are mostly limited. Obviously, the choice of Tunisian SMEs as a central research field is part of an approach with two objectives. First, through this research, we are trying to fill a research gap in studies on new trends in the management of SMEs in Tunisia. Next, we insist on the indisputable role of government support media for Tunisian SMEs given their future potential in the country's economic development.

Digital technologies rank first among the factors that can promote the growth of modern economies. Digital technologies are changing people's lives: the way they operate, socialize, communicate, and are educated (Deloitte, 2013). in short, these

\footnotetext{
* Corresponding author.

E-mail address: am.docteur@gmail.com (Amine Ben Hadj Hassine)
} 
technologies are changing all around us. Consequently, companies are obliged to follow these changes and adapt to the new environment if they want to keep and consolidate their market shares and avoid the risk of disappearance. However, the changes companies need to make can be partial or far-reaching.

In this paper, the empirical investigation was conducted through face-to-face interviews and by videoconference. Indeed, we believe that for this subject, qualitative research provides a better understanding of all the processes likely to explain the decisions and strategies of top management. The main results of this research show that the engagement of Tunisian SMEs in a digital transformation process has a positive impact on the overall performance and consequently on the competitiveness and sustainability of these companies.

\section{Digital Transformation: a conceptual framework}

Digital transformation or the fourth industrial revolution, in general, when we talk about the concept of revolution, we have the impression of talking about a sudden and radical change. Throughout history, revolutions have been the primary cause of profound change that has redefined modes of governance and leadership, economic systems, social structures, and ultimately the use of technology (Schwab, 2016). For Verhoef et al. (2019), digitization is a multidisciplinary mechanism involving changes in strategy, organization, information technology, supply chains and marketing.

Digitization is a still recent buzzword in academic and business fields (Verina \& Ttko, 2019). Currently, this new trend has become one of the most studied concepts in the literature of economics. Some studies like that of Ismail, Khater, and Zaki (2017) define it as a "process through which companies converge multiple new digital technologies, enhanced with ubiquitous connectivity, with the intention of reaching superior performance and sustained competitive advantage, by transforming multiple business dimensions, including the business model, the customer experience (comprising digitally enabled products and services) and operations (comprising processes and decision-making), and simultaneously impacting people (including skills talent and culture) and networks (including the entire value system)". Martinez (2019) sees things simpler since for him the "digitization journey" is a procedure in which organizations introduce, implement, and rationalize digital solutions.

Indeed, the concept of digital transformation refers to the nature of the changes made possible by the latest developments in the field of Information and Communication Technologies. Unlike all previous industrial revolutions, this fourth revolution commonly known as Industry 4.0 brings together characteristics of high speed, non-linearity, breadth, and depth in its occurrence (Schwab, 2017).

All definitions converge towards the same meaning: digitization is a strategic source of creation of added value (Schwab, cited in Martinez, 2019), However, the intersection of the two concepts of digitization and business model innovation is also $\mathrm{d}$ " of strategic importance since it evokes all the internal challenges related to the use of technological possibilities and digital solutions (Mezger, cited in Rachinger \& al., 2019).

Consequently, in order to maintain a comfortable level of growth in a highly competitive market, organizations have no choice. they are forced to include digitization as a main component when formulating their strategies (Hess \& al., 2016). Likewise, this prerogative will not guarantee the success of the digital transformation process since at the same time decision-makers must determine the degree of digitization necessary to achieve their objectives (Grover \& Kohli, cited in Matt \& al., 2015). Finally, it seems clear that organizations that want to survive in the coming decades are obliged to radically change their working methods due to rapid technological development (Gobble, 2018).

\section{Digital transformation challenges}

In the digital age, the business world is changing. Activities have become dematerialized, moving away from old working methods in favor of IT solutions and digital tools. Such a change may have provoked resistance and mistrust for some companies. Faced with this embarrassing situation, one can often find managers intimidated by the scale of the task, work teams hesitant to give up their old ways of working or who are simply afraid of change. So many psychological brakes that can sometimes slow down the implementation of innovative and effective solutions. However, good change management can overcome all these problems and take full advantage of the opportunities that this transition can present. Indeed, if the technological challenges are quite clear for most decision-makers, the challenges relating to the field of economics, or even management and social sciences should not be underestimated.

In what follows, we present what Lemoine $\&$ al. (2014) consider as major problems:

Technical issues: It is obvious that the success of the digital transformation process is directly linked to the company's ability to master and align technologies and their uses with the overall strategy and the resulting objectives. Likewise, other keys to success are added to these skills, such as professionalism in collecting and processing data from internal 
and external flows, or even access to the skills required for this change, or even the establishment loyalty and retention programs for them. Behind all these challenges lies a major problem: the governance of change, more concretely, of digital transformation. Certainly, the main objective is the improvement of value creation processes through new technologies, while mastering risk management and performance techniques (Bounfour \& Fernandez, 2015).

- Economic Issues: Digital technologies have revolutionized management science. Old theories inherited from previous centuries are no longer useful or at least they need to be revisited and updated. Likewise, working practices within companies as well as modes of governance are being renewed day after day, at an accelerated pace. Big Data, Blockchain, Internet of Things, are now assets of an intangible and intangible nature that must be considered all like the former assets of the company. Academics urgently need to find the appropriate means and techniques to manage these assets. Certainly, these are important assets which are not yet sufficiently valued by the markets.

- Human Issues: The upheavals due to digitization generate for human resources several challenges which are often difficult to meet due to the speed of change and the instability of strategies, objectives, and benchmarks. More than ever, digital transformation reinforces the need to reshape the work environment which should be focused on personalization, motivation, creativity and above all recognition and merit.

In addition to the technological problems mentioned above, the human factor is of undoubted importance for the success of the digital transformation (Herzog \& Bender, 2017). On a related note, a McKinsey study concluded that around $45 \%$ of tasks in the company can be automated, freeing up workers' time from routine and repetitive tasks and allowing them to focus more on really challenging tasks and creative. From a technical point of view, the fact that digitized processes are functioning correctly cannot guarantee the success of the transition. indeed, these stressful changes must be appropriated by employees, managers, and executives.

Many transformation processes have failed because participants do not want to join this movement, or they are afraid to use a new system, or they do not have the skills to integrate or simply because they do not have the support of their hierarchical superiors. The human aspect is still considered the weakest link in a digitization process (Carlsson, 2018). So, employees must be convinced by the change and its objectives. They must join this program unconditionally. Likewise, top management must ensure that the work environment supports innovation and change. It is simply a matter of establishing a new corporate culture.

- Ethics and social responsibility Issues: In addition to the issues of digital transformation mentioned above, it is necessary to highlight the ethical issues and those relating to the social responsibility of the company as well as ecological issues. Certainly, without this consideration, the success of the digital transformation process will be compromised or reduced in efficiency. In this regard, let's remember that the CSR concept supposes that a company is a social agent that is part of a global framework where managerial decisions and actions generate impacts and create relationships with stakeholders, society and the economic landscape.

Indeed, if we admire the speeches on the benefits of digital transformation, we can in no way ignore the voices that warn about structural risks such as, for example, the destruction of jobs (Brynjolfsson \& McAfee, 2012), or the security and protection of personal data or even the problem of transparency linked to the use of big data in companies of the future, which presupposes the establishment of a climate of trust in a hyper connected environment. Moreover, these data are considered as the black gold of the 21 st century and the new intangible asset of the company of the future. However, if the digital transformation imposes a new social contract between the company and its environment, it also implies new ethical, regulatory, and legal constraints that top management must imperatively take into account. Nowadays, the concept of corporate social responsibility, like many other paradigms, is outdated. From now on, it is about the digital responsibility of the company.

\section{Key determinants of digital transformation:}

In a research entitled "Digital transformation playground: literature review and framework of concepts", Pihir \& al. (2019) identified the key determinants of digital transformation that must be taken into account to improve the digital maturity of an organization and therefore guarantee the success of this transition process.

- Strategic orientation: This implies that the decision-makers at the strategic level of the organization are the first responsible for the process of change through a planning and a strategy whose approach is well clear and defined. Managers must ensure an optimal allocation of resources towards the achievement of objectives. Likewise, they must encourage all employees to join the digital transformation project.

- Customer centricity: New digital solutions have totally transformed the relationship between the company and its customers. New communication channels and new market monitoring and evaluation tools are now available to the company's marketing managers. Indeed, CRM, Big Data, social networks are components of digital marketing capable 
of monitoring, predicting, and influencing consumer behavior, making it possible to create new needs or, where applicable, to react at the appropriate time to different cases that may arise in the market.

- ICT and process infrastructure: The level of digital maturity of a company reflects its ability to be agile to face the various challenges generated by digital transformation. This maturity is assessed, among other things, by the skill of managers in using the most suitable digital technologies to change products, services, or entire processes.

- Talent, capability and capacity strengthening: The digital transformation should considerably affect work processes and the work environment in general (Pinzone \& al., 2017). In view of this, new technologies are expected to increase flexibility, efficiency and quality which will increase the need for new skills and competences (Jerman, Pejić Bach, \& Bertoncelj, 2018). We reiterate that it is important for management to have confidence in its vision and that its employees are capable of effectively leading this change.

- Innovation culture and organizational commitment: If Pihir \& al. (2019) have chosen to dissociate this determining key from the previous ones, we believe that it can be well integrated into the analyzes relating to Talent, capability and capacity strengthening. In this regard, the authors assume that employees must fully embrace the transformation process and managers must ensure that the work environment supports innovation and change.

To conclude, we assume that the digital transformation relies on three drivers which are customer orientation, operational process orientation and business model orientation.

\section{Research methodology}

Given the nature of the subject, this research is based on a research methodology that uses a qualitative approach. Indeed, qualitative analysis allows the exploration of phenomena linked to digitization, depending on and adaptation strategies to access it. The collection of information was established through questionnaires and individual interviews. The choice of the companies studied was made in a non-arbitrary manner to ensure that the selected case studies meet several criteria.

The timing of the preparation of this research was not the most appropriate for conducting face-to-face interviews due to the Corona virus and the accompanying safety and hygiene measures. Very few managers agreed to meet with us for a live interview. The interviews, semi-structured, were mainly conducted via videoconferencing tools such as Zoom, Microsoft Teams or Skype.

The general containment has forced several small and medium-sized companies to suspend their activities. In total, we contacted 75 executives by email and phone. Several of them had to apologize for not being able to respond to our request for not mentioned reasons. In the end, we managed to interview 20 leaders who expressed their interest in this topic and agreed to share their experiences.

Our sample has the following characteristics:

- 20 SMEs belonging to the sectors of textiles (3 companies), agri-foods (4 companies), Wholesale trade (3 companies), biochemistry and the pharmaceutical industry (4 companies), Communication and media (3 companies) and the packaging industry ( 3 companies);

- The managers interviewed (depending on their availability) are the founding owners (12 interlocutors), the sales or financial directors (4 interlocutors), the human resources director (1 interlocutor), the deputy or associate general manager ( 3 interlocutors);

- the companies have an average age of 10 years, a workforce of less than 100 employees and are spread throughout Tunisia.

Interview questions have been prepared in advance. These questions served as a guide to initiate discussion on various themes of our subject of study. In addition, additional questions were asked based on the answers of the interviewee to obtain a more complete answer. These interviews lasted on average about 30 minutes. However, all interviewees without exception insisted on anonymity.

Note that the representativeness of our sample compared to the number of Tunisian SMEs is limited. This was mainly due to the period of setting up our empirical survey as we have already mentioned above. However, this does not prevent this work from being considered as a first observation on the state of digitalization of Tunisian companies and at the same time a first guide for many directors for whom the concept, its challenges and its implications are still unclear. This research will be followed by other papers in which we will try to integrate new dimensions of digital transformation and specially to widen our sample as much as possible for a better representativeness. 


\section{Empirical results}

\subsection{Digital transformation: the Tunisian companies perception}

Digital transformation seems to be a priority on the agenda for Tunisian companies. During the transcription of the interviews, we noted the redundancy of the word priority since, for 17 managers, digital transformation is an essential priority for companies concerned with preserving their places in the market while benefiting from the advantages offered by this change. Conversely, based on our results, all managers cannot see clearly how to achieve this.

The variation between different companies in the perception of digital transformation is no longer marked, as 20 respondents say they are aware of the existence of the trend. In the 20 companies that made up our sample, the majority of departments are computerized, but the concepts and functions dedicated to digital are quite weak. Overall, only the 3 companies operating in the food industry and the one belonging to the packaging sector are equipped with software packages such as supply chain management, customer relationship management or the famous resources planning company. Indeed, the terms used by companies speak less of new technologies. Concerning the implementation of projects related to digital transformation, 6 managers indicated that digital transformation is part of their future strategic projects.

However, the interviews revealed that the main thrusts of these digitalization projects are not the same for all companies. 13 companies have focused on their presence on the web and have hired a team of specialists to set up and maintain professional websites while other companies have chosen to strengthen their presence on social networks like Facebook. In this regard, the survey revealed that only 4 companies have digitalization projects in progress, 2 companies having planned projects, but which have not yet started this process while the other companies do not have any digital projects. Moreover, the managers of these companies endorse this delay due to the financing problems which is non-existent or sometimes insufficient in all areas as mentioned by one of those managers: "There are few possibilities for funding this kind of transition process. we cannot commit to this drastic change without risk capital. In addition, an SME like ours does not always have access to information on these financing programs, especially since we do not have the skills required to benefit from them". This same opinion is shared by another leader who assumes that "There is huge potential and too much ambition among small businesses interested in research and development as well as innovation, but there is not enough funding and support opportunities for these small and fragile structures".

\subsection{Digital transformation: The opportunities offered for Tunisian SMEs}

The vast majority of companies questioned as part of this work have shown that the digital transformation will provide them with great benefits in several phases and in several stages, in particular in this context of improving the work chain, having access to other markets on an international scale, which will promote the export of their products, increase their turnover, improve the quality of their products and optimize costs. And finally, to have a good perception of the company.

In this sense, the main deductions drawn from the analysis of the interviews confirm what valuable research has confirmed since all managers have considered that what makes digitization a complex phenomenon is its disruptive nature, but which at the same time generates new opportunities and broad horizons for SMEs. In this regard, the manager of the packaging company affirms that digitization enables SMEs to increase the efficiency of their strategies as it enables them to consolidate and optimize their innovation efforts through the use of solutions and digital tools otherwise the company risks falling behind or being excluded from the market. He affirms: "We have planned our digitization project to automate our various processes, to optimize our value chain in partnership with all our partners. We have thought deeply about the reform of our corporate culture to guarantee the commitment of all employees to the change project. Thus, we have succeeded in saving costs, serving our customers better and improving our brand image. In any case, if we did not have an ambition to modernize our company, it was not easy to overcome".

\subsection{Digital transformation: Challenges and issues for Tunisian SMEs:}

In this context, the leaders of Tunisian SMEs interviewed in this survey unanimously agree that it is imperative to effectively take advantage of the strong presence of Tunisian consumers on social networks, more particularly on Facebook, to capture a new generation of customers but also to establish new contacts with suppliers and partners. For this, Tunisian SMEs should invest massively in research and development in order to find new ways of innovating their processes, their products and services in order to survive in a hyper competitive market.

Except for the firm operating in the Communication \& Media sector, the 19 other managers raised the problem of the shortage of specialized skills in digital technology as well as the lack of knowledge of digital tools.

Regarding the answers to questions relating to the risks and challenges of digital transformation, we noted that all managers consider that the main obstacles to the implementation of digital projects can be summed up in the omnipresence of a traditional corporate culture, including the values are archaic and out of date. The same respondents all agree that resistance 
to change can cripple any digital transformation process. Likewise, unanimously, it was reported that regulatory barriers are also seen as the primary obstacles to digitization.

In this regard, one of the managers of textile companies says that "it is foolish to talk about the benefits that digital transformation can generate in the absence of a favorable legal framework. Nowadays, there is no law concerning the establishment of electronic invoices, there is no law promoting digital signature as there is not yet a clear and detailed regulation concerning electronic payments and e- commerce in general". So, the government must take action to lighten the rules and procedures for adopting digital tools and to act as a guarantor to resolve the problem of financing SME digitization projects since all the managers interviewed noticed that traditional financial instruments are no longer suitable and must be revised in this case.

This observation is approved by the commercial manager of the company operating in the chemical industry sector. According to him, "digital transformation is a heavy investment, it is costly in terms of advanced technological equipment, restructuring and reorganization of processes or even in terms of specialized coaching while its benefits are only perceived in the longer term. Moreover, I am even certain that many managers think that the costs of this transformation could be greater than the benefits it will generate. In my opinion, this is why most Tunisian SMEs are reluctant to adopt and engage in the digitalization process."

In addition to all these problems revealed by our survey, by asking our interlocutors about their assessment of the ecosystem, we were able to understand that the insufficiency of equipment in modern digital infrastructure as well as the slowness of the implementation of solutions electronic payment, especially in foreign currencies, and digital security issues are also factors that disadvantage Tunisian SMEs in terms of digital maturity despite a strong awareness on the part of all actors of its importance and benefits.

Among the 11 sectors of activity studied, we noticed that the biotechnology, health services and chemical industry sectors are the most prepared to adopt digital transformation projects and to succeed in this adventure. The other sectors are lagging behind although the manufacturing sector is assumed to be in first place.

\section{Conclusion}

The technological shift of Tunisian SMEs involves a set of major challenges and must imperatively meet multiple organizational realities. Faced with this giant challenge as well as the imperative to remain competitive in their industry, top management must plan and implement strategies integrating the repercussions of this new type of change, action plans which are capable of generating better organizational and operational performance.

Unfortunately, our investigation revealed that there are many examples of SMEs that have been unable to keep pace with this change mainly for lack of skills to drive this transformation, for lack of strategic vision and proactivity besides the recurring problem of funding. We will dedicate these examples for a future research that will study the causes of failure of digital transformation processes and possibly recommendations to avoid certain problems or gaps that caused this failure.

This research can constitute a first guide for entrepreneurs or future entrepreneurs, mainly for small and medium-sized enterprises, to benefit from recommendations that can support their decision-making process in a highly competitive, highly digitalized, and uncertain environment.

The main results of this survey revealed that the level of digital maturity of Tunisian SMEs is too low compared to the economies of the northern shore of the Mediterranean. The Tunisian government is called upon to find solutions for major problems related to this digitization process such as the weakness of digital infrastructure, cybersecurity problems, lack of digital skills and access to finance deemed to be demotivating factors for any digital transformation project. On the other hand, SMEs should be aware that digitization could be a good opportunity to develop their activities and improve their performance. This study justified the importance of establishing a new organizational culture with a new vision and new values that can coexist with the new ecosystem.

This paper is one of the few studies that have tried to decipher the perception of digital transformation by Tunisian entrepreneurs, to understand the challenges of digitization for SMEs and to decipher the causes of delay in the adoption of digital tools by these companies. However, given the size of the sample studied and the critical period in which the survey was conducted, it is advisable to interpret the results of this investigation with caution and to take into account that they cannot be generalized given that SMEs Tunisian women represent almost 98\% of the country's economic landscape. Moreover, all of these limitations motivate us to broaden our research in order to achieve an adequate representability rate and integrate new dimensions or even to carry out comparative studies with neighboring countries. 


\section{References}

Belleguic, T., Coutard, J., \& Doueihi, M. (2011). Les enjeux de la réputation à l'ère du numérique. Sécurite et stratégie, 6(2), 22-27. https://doi.org/10.3917/sestr.006.0022

Bounfour, A., Fernandez, V., \& Waller, E. (2015). Cloud computing and organisational design: towards a comprehensive research agenda. Systèmes d'information management, 20(4), 3-10. https://doi.org/10.3917/sim.154.0003

Chaintreuil, J.N. (2015). Regards collectifs de RH sur la transformation digitale. Editions Diateino, French.

Chanias S, (2017). Mastering digital transformation: the path of a financial services provider towards a digital transformation strategy. European Conference of Information Systems, 25, $16-31$. https://aisel.aisnet.org/ecis2017_rp/2

Colbert, A., Yee, N., \& George, G. (2016). The digital workforce and the workplace of the future. Academy of Management Journal, 59(3), 731-739. https://doi.org/10.5465/amj.2016.4003

Colin, N., Landier, A., Mohnen, P., \& Perrot, A. (2015). Économie numérique. Notes du conseil d'analyse

économique, 7(26), 1-12. https://doi.org/10.3917/ncae.026.0001

Dussart, C. (2015). Modèles d'affaires: Transformation numérique en vue. Montréal. Revue de la Gestion, 40(1), 7984. https://doi.org/10.3917/riges.401.0079

Dudézert, A. (2018). La transformation digitale des entreprises. La Découverte, French.

Dorothée, E.K. (2017). Digital transformation and the world-class HR difference. Strategic HR Review, 16(2), 86-88. https://doi.org/10.1108/SHR-01-2017-0001

Fuchs, C., \& Fisher, E. (2015). Introduction : valeur et travail à l'ère numérique. Dans Reconsidérer la valeur et le travail à l'ère numérique. Palgrave Macmillan, Londres.

Gadille, M., \& Jaujard, F. (2015). Déchiffrer les savoirs des acteurs locaux et créer la collaboration entre les parties prenantes. Changement et grands projets Des choix engagés, Presses de l'Université du QuébecPUQ

Ismail M.H., M. Khater and M. Zaki, "Digital Business Transformation and Strategy: What Do We Know So Far?", University of Cambridge, Working Paper ITWeb IoT Survey

Jaujard, F. (2015), Projet de communication “Usine connectée”, Colloque Industrie du Futur, Institut Mines Télécom, 26 novembre 2015.

Jerman A., Pejic Bach M., Bertoncelj A., (2018), A Bibliometric and Topic Analysis on Future Competences at Smart Factories, September 2018, Machines 6(3):41

Kane, G. C.; D. Palmer; A. N. Phillips; D. Kiron et N. Buckley (2015), "Strategy, Not Technology, Drives Digital Transformation", MIT Sloan Management Review and Deloitte University Press, July 2015.

Kessler, T. et C. Buck (2016), How Digitization Affects Mobility and the Business Models of Automotive OEMs. Springer International Publishing Switzerland 2016. A. Khare et al. (eds.), Phantom Ex Machina.

Lemoine, C. (2014). Se former au bilan de compétences-4e édition : Comprendre et pratiquer la démarche. Dunod.

Matt, Christian; Hess, Thomas; and Benlian, Alexander (2015) "Digital Transformation Strategies," Business \& Information Systems Engineering: Vol. 57: Iss. 5, 339-343.

McAfee A, Brynjolfsson E., (2012), Big Data: The Management Revolution, Harvard Business Review 90(10):60-6, 68, 128

Patel, K., and Mc Carthy, M. P (2000). Digital transformation: the essentials of e-business leadership. McGraw-Hill Professional.

Pihir I., Katarina Tomicic-Pupek, Martina Tomičić Furjan (2019), Digital transformation playground: literature review and framework of concepts Journal of Information and Organizational Sciences 43(1):33-48

Pinzone M., Fantini P., Perini S., Garavaglia S., Taisch M., Miragliotta M. (2017), Jobs and Skills in Industry 4.0: An Exploratory Research, Conference: IFIP International Conference on Advances in Production Management Systems

Poels, A., Rudmin, D., Benaissa, A., and Poirel, D. (2015). Localization of flow separation and transition over a pitching NACA0012 airfoil at transitional Reynolds numbers using hot-films. Journal of Fluids Engineering, 137(12). 